\title{
Off-label Use of Drugs in Childhood Asthma
}

\author{
António J Cabral'1,2 and Mário Morais-Almeida ${ }^{3,4}$ \\ 1. Specialist in Paediatrics, Funchal Central Hospital, Madeira; 2. Allergy Center, CUF Descobertas Hospital, Lisbon, Portugal; 3. Head of the Allergy Center, \\ CUF Descobertas Hospital and CUF Infante Santo Hospital, Lisbon, Portugal; 4. CINTESIS - Center for Research in Health Technologies and \\ Information Systems - Faculty of Medicine, University of Porto, Porto, Portugal
}

\begin{abstract}
Asthma is among the most common illnesses in childhood and may require off-label drug use for adequate symptom control. Several studies have assessed that this use is common mainly due to a lack of clinical research. The leading concerns are the increased risk of adverse drug reactions and prescription errors. However, off-label prescriptions are not necessarily incorrect. The European Medicines Agency released the Paediatric Regulation to promote research in the medicines for children; yet, recent data suggest only a minor impact.

\section{Keywords}

Off-label, asthma, children, paediatric regulation

Disclosure: António J Cabral and Mário Morais-Almeida have no conflicts of interest to declare. No funding was received in the publication of this editorial. Open Access: This article is published under the Creative Commons Attribution Noncommercial License, which permits any non-commercial use, distribution, adaptation and reproduction provided the original author(s) and source are given appropriate credit.

Received: 28 July 2015 Published Online: 17 August 2015 Citation: European Respiratory and Pulmonary Diseases, 2015;1(1):16-7 DOI: 10.17925/ERPD.2015.01.01.16 Correspondence: Mário Morais-Almeida, Allergy Center, CUF-Descobertas Hospital, 1998-018 Lisbon, Portugal. E: mmoraisalmeida@netcabo.pt
\end{abstract}

Asthma is among the most common respiratory illnesses in childhood and frequently requires the use of long-term control medication. Even though less than half of the children represent true therapyresistant asthma, they may require off-label use for adequate symptom control. Many drugs used in the treatment of allergic diseases are not appropriately studied in the paediatric population, especially in infants and younger children. Nonetheless, their off-label use, that is, use outside the formal indications authorised by the regulatory authorities, in a different age group dose, or indication ${ }^{1}$ is common in many paediatric illnesses, such as allergic disease, in up to $37 \%$ of paediatric outpatients and in up to $62 \%$ of children treated in paediatric hospital wards. ${ }^{2}$ This brings to light many health concerns, such as increased risk of adverse drug reactions and prescription errors - namely dosage errors, particularly in younger children and infants. ${ }^{3}$ However, off-label prescriptions are not necessarily incorrect, ${ }^{4}$ and may even be appropriate when there is no alternative treatment, when the likely benefits outweigh the potential risks or when conventional treatments are unable to achieve control of the disease. ${ }^{5}$ New therapeutic uses may also be described, and data on the efficacy and safety of the drug being used may be collected. ${ }^{6}$

Several studies have assessed the paediatric use of drugs through cohort and cross-sectional studies. A population-based cohort study carried out in primary care units in Holland evaluated the prescribing of respiratory drugs in 2,502 children in which $37 \%$ of all prescriptions were off-label, and $39 \%$ in this group were prescriptions for asthma.? Data from the Task force in Europe for Drug Development for the Young (TEDDY), comparing the use of anti-asthmatic drugs in children in Holland, Italy and the UK, established that off-label use of beta2agonists and inhaled corticosteroids (ICS) is frequent. ${ }^{8}$ A study carried out in Portugal in preschool children showed that $35 \%$ of prescriptions for allergic disease were considered off-label, and this occurred most frequently in children under the age of $2(74 \%) .{ }^{9}$ This study also revealed that off-label use may vary with national regulatory authorities with examples given for nasal mometasone, whose use in rhinitis, a very prevalent asthma comorbidity, is allowed in the US by the Food and Drug Administration (FDA) from 2 years old, while in Europe it is only approved for children 6 years or older. In addition, levocitirizine is approved by the FDA from 6 months old while the European Medicines Agency (EMA) maintains its use only over the age of $2 .{ }^{10}$

While off-label use can be justified, it involves obtaining informed consent from the parents or guardian. In addition, while this information is important for patient and caregiver adherence, it is frequently omitted. The majority of paediatricians do not seek informed consent, or inform the parents or guardian that they were prescribing an off-label medicine, and only one-third admits to informing a child's general practitioner of this prescription. ${ }^{11}$

One must consider why off-label use in children is so common. It is mainly due to lack of clinical research. ${ }^{12}$ Pharmaceutical companies see little benefit with only a few drugs representing a large enough economic interest. This particular population demands specific medical techniques and appropriate equipment that can be difficult to execute or even authorise. Lastly, there are ethical implications due to potential risks that hinder clinical trials. ${ }^{13}$

In an effort to oppose this course, EMA released the Paediatric Regulation (EC no. 1902/2006), in order to ensure high-quality research in the development of medicines for children and, over time, have the majority of drugs used in children specifically authorised for such use. This would guarantee the availability of better information on these medicines. To achieve this, a Paediatric Committee was set up that required companies to submit data in accordance with an appropriate 
Paediatric Investigation Plan. The pharmaceutical companies are then rewarded with a 6-month extension to the Supplementary Protection Certificate and, in the case of orphan drugs, an extra 2 years of market exclusivity added to the existing 10 years awarded under the European Union's Orphan Regulation. ${ }^{14}$ Despite these efforts, recent data clearly show that this legislation has had only a minor impact on the authorising status of drugs used commonly in paediatric inpatients, particularly in children younger than 2 years. ${ }^{15}$

Very young children present particular challenges in asthma treatment. Often there is an overlap of recurrent wheezing and asthma phenotypes leading to controversies in diagnosis and therapeutic decisions. Side effects of some therapeutic options need also be considered. Inhaler types and the child's ability to use them correctly limit some treatments; for example, dry-powder inhalers are not licensed for preschoolers. Lastly, newer drugs, for example, mometasone and ciclesonide, are rarely originally approved under the age of 12 . Still most physicians believe that off-label prescribing is adequate, and they do it believing that the benefits outweigh the risks. However, due to lack of evidence, they are frequently unaware of the true balance. ${ }^{1}$

The Global Initiative for Asthma (GINA) and the Expert panel report 3 (EPR3) Guidelines on Asthma provide recommendations for asthma treatment for all age groups and are nowadays widely followed by physicians. ${ }^{16,17}$ Nonetheless, evidence supporting recommendations for preschoolers is limited. These guidelines propose ICS as the mainstay treatment in asthma; however, upper-dose limits in children are not often given, and most recommendations are mainly based on experience with adults and older children, with dose responses not being well studied. Then again, guidelines are recommendations on appropriate management, diagnosis and treatment. They differ between each other and vary widely between countries and should not replace a clinician's knowledge and

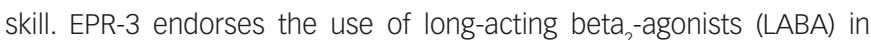
persistent asthma, if control is not achieved with ICS, but points out that these drugs are not adequately studied in children under the age of 4 . On the other hand, GINA alerts that LABA are not approved under the age of 5 and advises the use of antileukotrienes (ALT) as an alternative. Despite these suggestions, off-label use of LABA remains high with over $30 \%$ of children under the age of 4 being prescribed these drugs for severe asthma not controlled with ICS with or without ALT. ${ }^{18}$

So what can be done in the future? There is an increasing need for new research for the improvement of drug use and safety in children, and this can only be achieved by well-designed clinical studies. As such, the pharmaceutical industry and academic organisations must be encouraged to research new drugs and study the existing ones in the market for use in paediatric age. Likewise, by enforcing more awareness on off-label prescription with detailed information on the drugs used, dosages, routes of administration and adverse effects, reliable data could be obtained for further evaluation of the safety and efficacy of these drugs. This is notably true in younger children with whom more complex studies are not feasible for practical and/or ethical reasons. Publication and distribution of this information is critical for the acquisition of new safety data, approval of new dosages, clinical indications and use in younger children as well as reducing off-label drug use that, although often appropriate, is not without risks.
1. Gazarian M, Kelly M, McPhee JR, et al., Off-label use of medicines: consensus recommendations for evaluating medicines: consensus recommendations for
appropriateness, Med J Aust, 2006;185:544-8.

2. Pandolfini $C$, Bonati $M, A$ literature review on off-label drug use in children, Eur J Pediatr, 2005;164:552-8.

3. Choonara I, Conroy S, Unlicensed and off-label drug use in children: implications for safety, Drug Saf, 2002;25:1-5.

Collier J, Paediatric prescribing: using unlicensed drugs and medicines outside their licensed indications, Br $J$ Clin Pharmacol, 1999;48:5-8.

5. Committee on Drugs, American Academy of Pediatrics, uses of drugs not described in the package insert (off-label uses), Pediatrics, 2002;110:181-3.

6. Bennett WM, Off-label use of approved drugs: therapeutic opportunity and challenges, I Am Soc Nephrol, 2004;15:830-1.

7. 't Jong GW, Eland IA, Sturkenboom MC, et al., Unlicensed and off-label prescription of respiratory drugs to children,

\section{Eur Respir J, 2004:23:310-3.}

8. Sen EF, Verhamme KM, Neubert A, et al., Assessment of pediatric asthma drug use in three European countries; a TEDDY study, Eur J Pediatr, 2011;170:81-92.

9. Morais-Almeida M, Cabral AJ, Off-label prescribing for allergic diseases in pre-school children, Allergol Immunopatho (Madr), 2014;42:342-7.

10. Silva D, Ansotegui I, Morais-Almeida M, Off-label prescribing for allergic diseases in children, World Allergy Organ J, 2014;7:4.

11. McLay JS, Tanaka M, Ekins-Daukes S, et al., A prospective questionnaire assessment of attitudes and experiences of off label prescribing among hospital based paediatricians, Arch Dis Child, 2006;91:584-7.

12. Meadows $M$, Drug research and children, FDA Consum, 2003;37:12-7.

13. Steinbrook R, Testing medications in children, N Eng/ J Med, 2002;347:1462-70.
14. Dunne J, The European Regulation on medicines for paediatric use, Paediatr Respir Rev, 2007:8:177-83.

15. Lindell-Osuagwu L, Hakkarainen M, Sepponen K, et al ., Prescribing for off-label use and unauthorized medicines in three paediatric wards in Finland, the status before and after the European Union Paediatric Regulation, J Clin Pharm Ther. 2014;39:144-53

16. Global Strategy for Asthma Management and Prevention Available at: http://www.ginasthma.org (accessed on 26 July 2015).

17. National Asthma Education and Prevention Program, Third expert panel on the diagnosis and management of asthma. Expert panel report 3: guidelines for the diagnosis and management of asthma. Available at: http://www.ncbi.nIm. nih.gov/books/NBK7232/ (accessed on 26 July 2015).

18. Cabral A, Morais-Almeida $M$, Inhaled long acting beta agonists prescription for asthma in pre-school children, Allergy, 2014;69(Suppl. 99):520-1 (abstract). 